\title{
Renal Cell Carcinoma as an Incidental Finding in Firefighters: A Case Series
}

\author{
Kyle W. Geiger ${ }^{1}$, Tanner J. Wright ${ }^{1}$, Levi Deters ${ }^{2}$ \\ 1. Medicine, Elson S. Floyd College of Medicine, Washington State University, Spokane, USA 2. Urology, Spokane \\ Urology, Spokane, USA
}

Corresponding author: Kyle W. Geiger, kyle.geiger@wsu.edu

\begin{abstract}
The link between cancer, including cancers of the kidney, and occupational exposure in firefighters has been well established. Renal cell carcinoma has a tendency to present incidentally on imaging rather than with the classic symptoms of flank pain and hematuria. In this case series, we identify four firefighter patients, all of whom initially presented with a kidney tumor as an incidental finding. We examine the absence of other risk factors in these patients along with current screening guidelines. This report aims to detail how these tumors present incidentally as well as evaluate the current screening guidelines in an effort to build awareness within this population. Patient demographics, risk factors, length of firefighting career, final pathology, and postoperative recurrence were evaluated. Four males underwent successful partial or total nephrectomy. All who have had follow-up have been tumor free with renal function intact. None are dialysis dependent. The role of routine renal imaging of this population is explored.
\end{abstract}

Categories: Urology, Oncology, Public Health

Keywords: renal cell carcinoma, firefighters, occupational medicine

\section{Introduction}

In 2019 , there were an estimated 73,820 cases and 14,770 deaths from cancers of the kidney and renal pelvis [1]. Of these cancers, renal cell carcinoma (RCC) is the most common. RCC typically presents in the sixth to eighth decade of life. One study cites a median age of 64 years with just $4.4 \%$ of patients presenting in the age range of 20 to 40 years [2]. It is established that firefighters are at increased risk for a number of types of cancer including cancers of the kidney [3-5]. This link is highlighted by occupational exposure to toxic substances [3]. Other documented risk factors include genetic predisposition/hereditary disorders, obesity, smoking, and various nephrotoxic industrial chemicals [6]. Routine screening may be indicated for populations with exposure and identifiable risk factors [7]. In this study, we examine a series of RCC among young firefighters in the Pacific Northwest who had a diagnosis of RCC after a tumor was found on imaging as an incidental finding. We examine the absence of other risk factors in these patients along with current screening guidelines. This report aims to describe how these tumors present incidentally as well as evaluate

Received 06/26/2020

Review began 06/30/2020 Review ended 07/11/2020 Published 07/18/2020

() Copyright 2020

Geiger et al. This is an open access article distributed under the terms of the Creative Commons Attribution License CC-BY 4.0., which permits unrestricted use, distribution, and reproduction in any medium, provided the original author and source are credited. the current screening guidelines in an effort to build awareness within this population.

\section{Case Presentation}

\section{Materials and methods}

A retrospective analysis was completed through our clinic's electronic healthcare record. We searched for patients who were diagnosed with RCC with a history of a firefighting career. Records from 2014 to 2019 were analyzed. Four total patients were identified with a median age of 36.5 years at detection of tumor (mean 40.75, range 31-58). Demographics, risk factors, and imaging were gathered and imported into a Microsoft Excel file. A Qualtrics ${ }^{\mathrm{TM}}$ online survey tool was developed and used to gather information about length of firefighting career. This information is presented in Table 1 . 


\section{Cureus}

\begin{tabular}{|c|c|c|c|c|c|}
\hline Case & Gender & Age & Length of fire career (years) & Smoking history & BMI \\
\hline 1 & Male & 38 & 18 & None & 28.1 \\
\hline 2 & Male & 59 & 40 & None & 30.8 \\
\hline 3 & Male & 35 & 19 & None & 30.4 \\
\hline 4 & Male & 31 & 7.5 & None & 28.5 \\
\hline
\end{tabular}

\section{TABLE 1: Demographics and Risk Factors}

BMI, body mass index

\section{Case presentations}

Case 1

A 38-year-old male with a history of chronic back pain underwent lumbar imaging. A 4-cm solid enhancing right lower pole renal mass was found incidentally (Figure 1). He was a professional firefighter for 18 years. His grandmother had kidney cancer at age 75 years. He denied gross hematuria and weight loss. The patient underwent robotic-assisted right partial nephrectomy. Pathology results showed T1a clear cell carcinoma with negative margins.

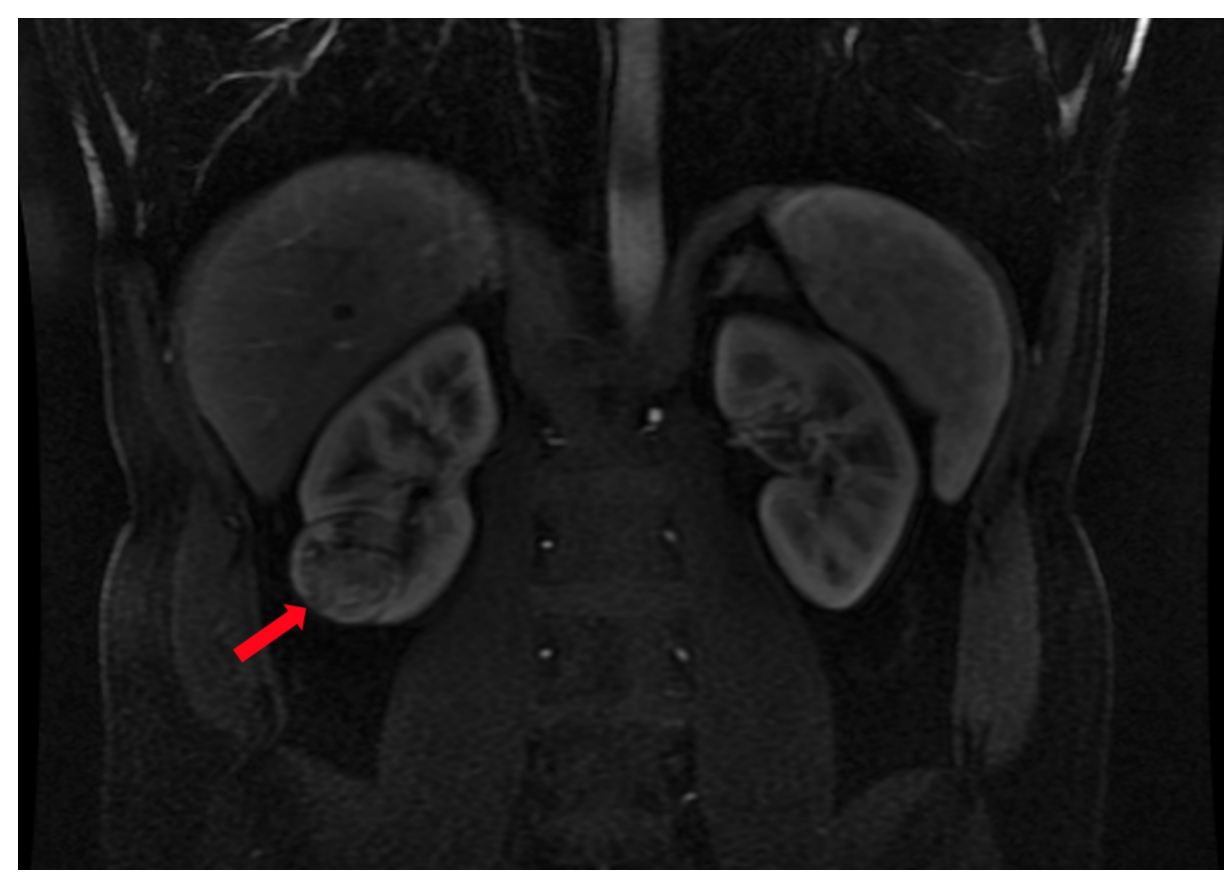

FIGURE 1: MRI showing image of right lower pole renal mass (red arrow)

Case 2

A 58-year-old male with a history of papillary mucinous neuroendocrine tumor of the pancreas was found to have a renal mass on imaging for pancreatic disease. He was a professional firefighter for over 40 years. He had no family history of renal cancer. He denied gross hematuria and weight loss. Imaging showed an approximately 4 -cm cystic lesion with septations and some enhancing components (Figure 2). The patient underwent a robotic-assisted right partial nephrectomy. Pathology results showed T1b clear cell carcinoma with negative margins. CT at four-month follow-up showed no suspicions lesions. 


\section{Cureus}

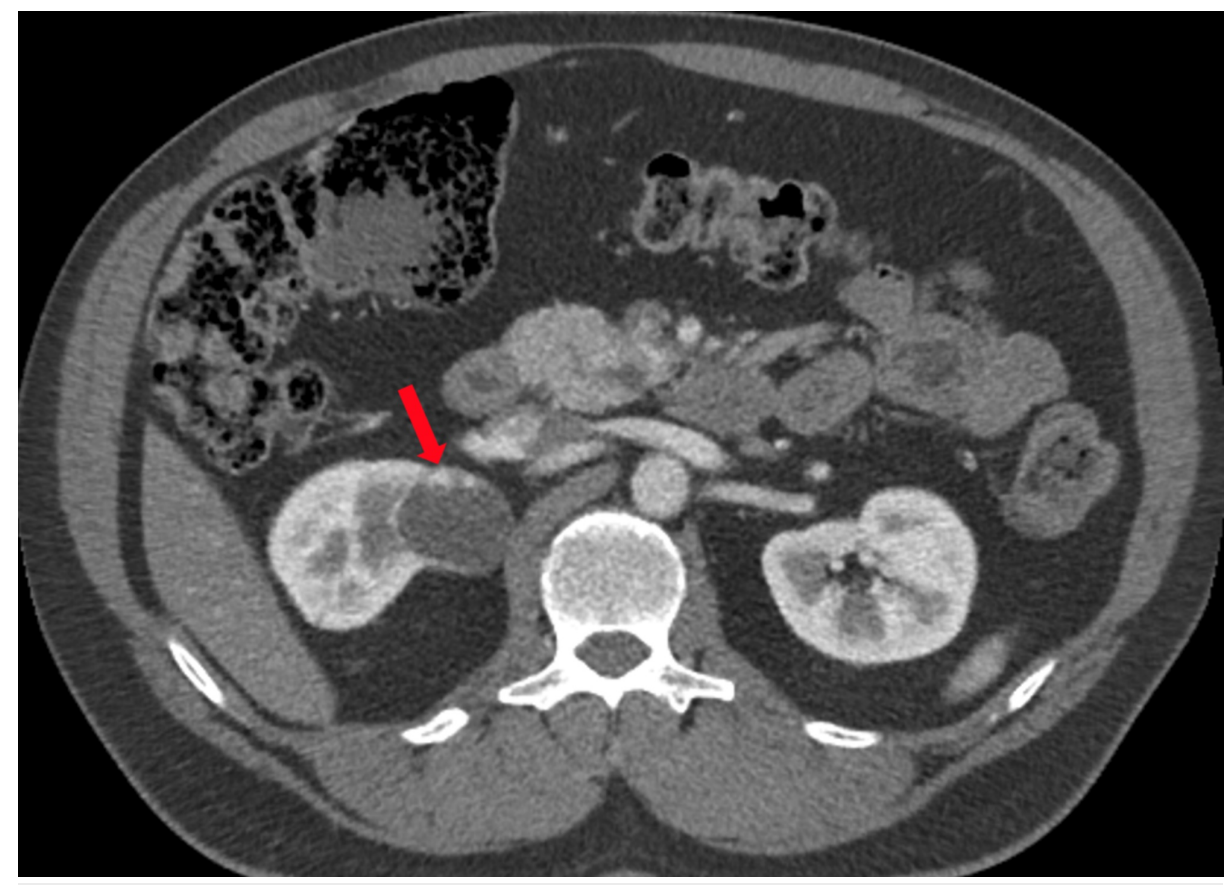

FIGURE 2: CT of the abdomen showing right renal mass (red arrow)

Case 3

A 35-year-old male who initially presented with calcium oxalate renal stones had a follow-up ultrasound that showed a $2.4-\mathrm{cm}$ hyperechoic area in the left kidney. The patient then underwent MRI and was found to have a 3 -cm mass. He had no family history of kidney cancer. He was a professional firefighter for 19 years. The patient underwent an open left partial nephrectomy. Pathology results showed T1a clear cell carcinoma with negative margins. CT at four-month follow-up showed no suspicions lesions.

Case 4

A 31-year-old male admitted from emergency department for gastroenteritis underwent CT with contrast showing a 3-cm enhancing left renal mass (Figure 3). He had no family history of kidney cancer. He denied gross hematuria and weight loss. He was a firefighter for seven and a half years. The patient underwent a laparoscopic left radical nephrectomy. Pathology results showed T1a clear cell carcinoma with negative margins. CT showed no suspicious lesions at seven months. 


\section{Cureus}

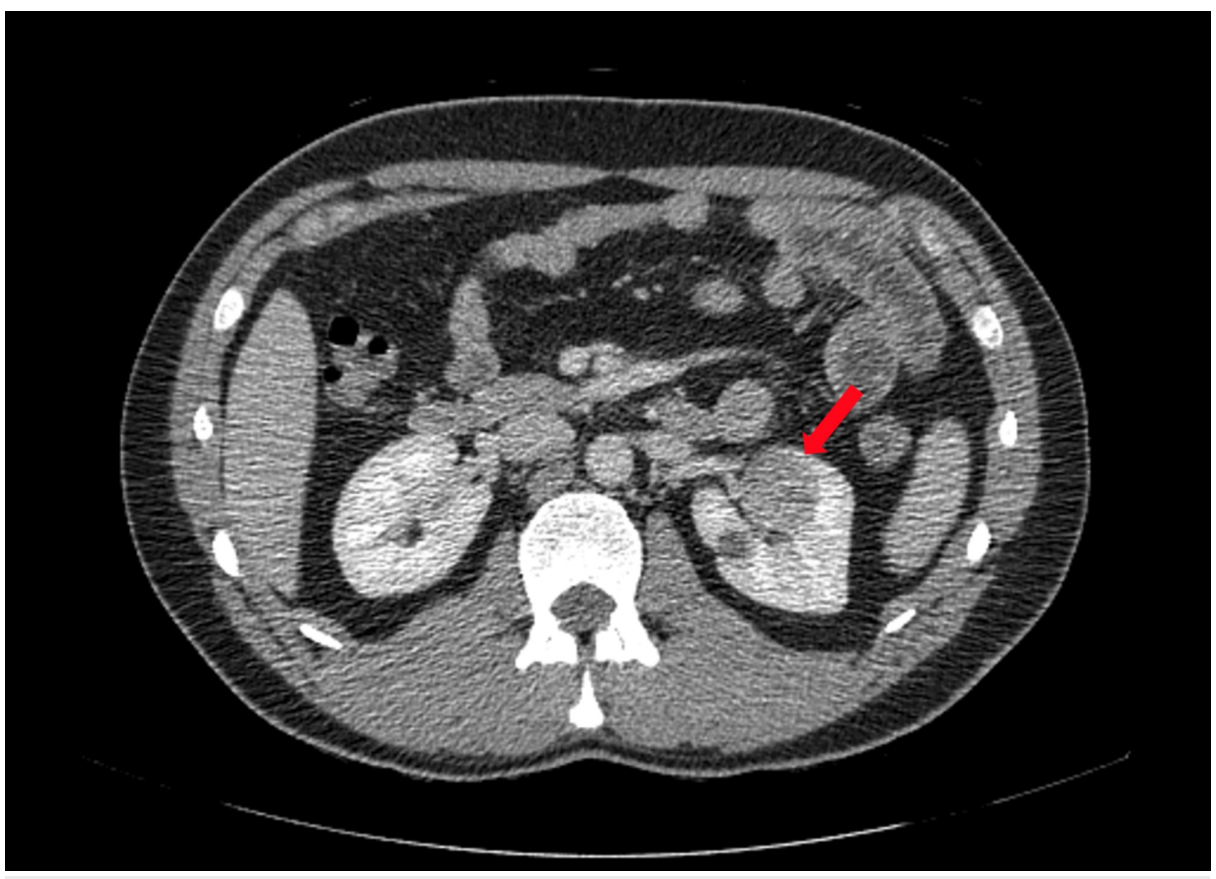

FIGURE 3: CT showing left renal mass (red arrow)

\section{Discussion}

This small series shows examples of RCC in firefighters within our community. We detail the diagnosis of RCC via incidental findings and subsequent treatment in this population. We present four patients, without other obvious risk factors and/or clinical symptoms, who were diagnosed with RCC after imaging for reasons other than routine screening (back pain, nephrolithiasis, etc.).

The literature has established that firefighters are at an increased risk for a variety of cancers including those of the kidney [3-5]. The mechanism for this increased risk is beyond the scope of our review, but is suspected to be due to exposure to carcinogens and possible genetic changes as a result [8]. RCC is one of the deadliest urological cancers. The Surveillance, Epidemiology, and End Results (SEER) database found an incidencebased mortality rate at $5.3 \%$ [9]. Recent studies within the firefighter population have recommended improving preventative measures [10]. Current screening methods and protocols for firefighters in our community are set by the National Fire Protection Association (NFPA) 1582: Standard on Comprehensive Occupational Medical Program for Fire Departments [11]. The NFPA recommends a yearly blood draw that screens for blood urea nitrogen (BUN), creatinine, and electrolyte abnormalities. They also recommend annual urinalysis for microscopic hematuria. However, renal function as measured by BUN, creatinine, and electrolyte abnormalities is not an established screening method for RCC. Other studies have found urinary dipstick is an inadequate test for RCC due to low sensitivity and specificity [12]. Renal ultrasound is an attractive option as a screening tool for RCC. Ultrasound is non-invasive, inexpensive, and widely used in the urological setting. A recent review of screening methods reports that ultrasound enables the detection of $85 \%-100 \%$ tumors of $>3 \mathrm{~cm}$ in size, and $67 \%-82 \%$ of tumors $2-3 \mathrm{~cm}$ in size [7]. The same study reports ultrasound as less sensitive and specific compared to CT; however, we suggest this is outweighed by cost, convenience, and lack of radiation exposure.

All of our cases found renal masses incidentally, demonstrating a possible role for routine imaging. Other studies have found RCC is diagnosed incidentally over $50 \%$ of the time [12,13]. In addition, routine screening may be indicated for populations with exposure and identifiable risk factors such as firefighters [7].

Evaluation of routine screening methods for kidney cancer may be supported in this population. We suggest a larger scale study examining the cost-benefit of ultrasound screening for RCC in our firefighter population.

Our study does not examine epidemiological data due to a limited sample size. This case series only provides an example of these patients in one small clinic in the Pacific Northwest. Other studies are needed to examine this relationship in the broader Pacific Northwest and United States.

\section{Conclusions}

Four of our firefighter patients were diagnosed with RCC via incidental findings on imaging. These cases highlight the possible need for additional screening in firefighters. There are limited studies that examine the role of routine renal imaging in this at risk population. We suggest a larger scale study examining the 


\section{Additional Information \\ Disclosures}

Human subjects: Consent was obtained by all participants in this study. Washington State University issued approval IRB \#17866-001. This project was deemed "exemption status" by the Washington State University IRB in November 2019. . Conflicts of interest: In compliance with the ICMJE uniform disclosure form, all authors declare the following: Payment/services info: All authors have declared that no financial support was received from any organization for the submitted work. Financial relationships: All authors have declared that they have no financial relationships at present or within the previous three years with any organizations that might have an interest in the submitted work. Other relationships: All authors have declared that there are no other relationships or activities that could appear to have influenced the submitted work.

\section{References}

1. SEER. Cancer stat facts: kidney and renal pelvis cancer . (2020). Accessed: March 2, 2020: https://seer.cancer.gov/statfacts/html/kidrp.html.

2. Siemer S, Hack M, Lehmann J, Becker F, Stöckle M: Outcome of renal tumors in young adults . J Urol. 2006, 175:1240-1243. 10.1016/S0022-5347(05)00696-8

3. Guidotti TL: Evaluating causality for occupational cancers: the example of firefighters . Occup Med. 2007, 57:466-471. 10.1093/occmed/kqm031

4. Kang D, Davis LK, Hunt P, Kriebel D: Cancer incidence among male Massachusetts firefighters, 1987-2003. Am J Ind Med. 2008, 51:329-335. 10.1002/ajim.20549

5. Tsai RJ, Luckhaupt SE, Schumacher P, Cress RD, Deapen DM, Calvert GM: Risk of cancer among firefighters in California, 1988-2007. Am J Ind Med. 2015, 58:715-729. 10.1002/ajim.22466

6. Capitanio U, Bensalah K, Bex A, et al.: Epidemiology of renal cell carcinoma. Eur Urol. 2019, 75:74-84. 10.1016/j.eururo.2018.08.036

7. Rossi SH, Klatte T, Usher-Smith J, Stewart GD: Epidemiology and screening for renal cancer. World J Urol. 2018, 36:1341-1353. 10.1007/s00345-018-2286-7

8. Jeong KS, Zhou J, Griffin SC, et al.: MicroRNA changes in firefighters . J Occup Environ Med. 2018, 60:469474. 10.1097/JOM.0000000000001307

9. Saad AM, Gad MM, Al-Husseini MJ, Ruhban IA, Sonbol MB, Ho TH: Trends in renal-cell carcinoma incidence and mortality in the United States in the last 2 decades: a SEER-based study. Clin Genitourin Cancer. 2019, 17:46-57.e5. 10.1016/j.clgc.2018.10.002

10. Jalilian H, Ziaei M, Weiderpass E, Rueegg CS, Khosravi Y, Kjaerheim K: Cancer incidence and mortality among firefighters. Int J Cancer. 2019, 145:2639-2646. 10.1002/ijc.32199

11. National Fire Protection Association. NFPA 1582: standard on comprehensive occupational medical program for fire departments. (2020). Accessed: March 3, 2020: https://www.nfpa.org/codes-andstandards/all-codes-and-standards/list-of-codes-and-standards/detail?code=1582.

12. Luciani LG, Cestari R, Tallarigo C: Incidental renal cell carcinoma-age and stage characterization and clinical implications: study of 1092 patients (1982-1997). Urology. 2000, 56:58-62. 10.1016/s00904295(00)00534-3

13. Rabjerg M, Mikkelsen MN, Walter S, Marcussen N: Incidental renal neoplasms: is there a need for routine screening? A Danish single-center epidemiological study. APMIS. 2014, 122:708-714. 10.1111/apm.12282 